IRA-International Journal of Education \& Multidisciplinary Studies

ISSN 2455-2526; Vol.11, Issue 01 (April, 2018)

Pg. no. 32-42.

Institute of Research Advances

http://research-advances.org/index.php/IJEMS

\title{
Issues in Contemporary Management of Secondary Schools in Benue State of Nigeria
}

\author{
Dr. Alabar, T. Timothy ${ }^{1 \#}$, Dr. Gbande, I. Richard ${ }^{2}$, Mrs. Lim, T. Deborah ${ }^{3}$ \\ ${ }^{1}$ Department of Business Management, Benue State University, Makurdi-Nigeria. \\ ${ }^{2}$ Department Business Management, University of Jos-Nigeria. \\ ${ }^{3}$ Board of Internal Revenue, Makurdi-Nigeria.
}

\# corresponding author.

Type of Review: Peer Reviewed.

DOI: http://dx.doi.org/10.21013/jems.v11.n1.p3

\section{How to cite this paper:}

Timothy, A.T., Richard, G.I., Deborah, L.T. (2018). Issues in Contemporary Management of Secondary Schools in Benue State of Nigeria. IRA International Journal of Education and Multidisciplinary Studies (ISSN 2455-2526), 11(1), 32-42.doi: http://dx.doi.org/10.21013/jems.v11.n1.p3

\section{(C) Institute of Research Advances.}

\section{(cc) $\mathrm{BY}-\mathrm{NO}$}

This work is licensed under a Creative Commons Attribution-Non Commercial 4.0 International License subject to proper citation to the publication source of the work.

Disclaimer: The scholarly papers as reviewed and published by the Institute of Research Advances (IRA) are the views and opinions of their respective authors and are not the views or opinions of the IRA. The IRA disclaims of any harm or loss caused due to the published content to any party.

Institute of Research Advances is an institutional publisher member of Publishers Inter Linking Association Inc. (PILA-CrossRef), USA. The institute is an institutional signatory to the Budapest Open Access Initiative, Hungary advocating the open access of scientific and scholarly knowledge. The Institute is a registered content provider under Open Access Initiative Protocol for Metadata Harvesting (OAI-PMH).

The journal is indexed \& included in WorldCat Discovery Service (USA), CrossRef Metadata Search (USA), WorldCat (USA), OCLC (USA), Open J-Gate (India), EZB (Germany) Scilit (Switzerland), Airiti (China), Bielefeld Academic Search Engine (BASE) of Bielefeld University, Germany, PKP Index of Simon Fraser University, Canada. 


\begin{abstract}
The world is undergoing nothing less than a major revolution in the way people spend their time and thought on the future of their endeavors. Perhaps, the most important mental and spiritual principle ever discovered is that you become what you think about most time and the actions and inactions you put in place in managing the resources available to you. In view of the fact that resources abound everywhere, they may have little or no value unless you pull out the essentials peculiar to your needs and apply it appropriately. The management of these resources can make you happy or sad, distracted or depressed, popular or unpopular, confident or insecure, positive or negative, successful or unsuccessful, powerful or powerless, victim or victor, a hero or a coward. The management style adopted by an executive determines the level employees feel and the seeds of success that will be planted. As the world moves from the era of things to the mental age, it will be only those that maximally apply the most impressing management principles that will scale the navigational flexibilities of our time. It is on the strength of this that this study is designed conceptually to unveil issues of contemporary management of secondary schools in Benue state of Nigeria. The paper is therefore structured in the following sub-headings: introduction, types of management styles, types of motivational programmes in the workplace, team building, and tips for team building, challenges of teamwork and a conclusion is drawn.
\end{abstract}

Keywords: Contemporary management, management styles, team building, motivational programmes, Secondary schools, Benue state, Nigeria.

\title{
INTRODUCTION
}

As the society grows and people began forming groups to accomplish aims they couldn't achieve as individuals, managing becomes essential in ensuring the coordination of individual efforts. But it is worthy of note that the crux of every management job lies in the job-holder's capacity to obtain the commitment of people towards achieving the purpose for which they stand for.

Management as a concept has evoked an intense interest or attraction in human existence for centuries, which attracted a lot of consideration from practitioners and social scientists. In the words of Weihrich and Koontz (1993), management can be seen as the process of designing and maintaining an environment in which individuals, working together in groups, efficiently accomplish selected aims.

The works of practicing mangers- such as Taylor and Fayol and the social scientists such as Mayo and McGregor contributed immensely to our understanding of management theory.

Practicing managers tend to reflect upon, and theories about their personal experiences of management with the object of producing a set of rational principles of management which could be applied globally in order to achieve organizational efficiency. The resultant theory of this school of thought was concerned primarily with the structuring of work and organization, rather than with human motivation or organization culture, for example. This theory was however prescriptive in nature i.e. they set out what managers ought to do in order to fulfill their leadership function within their organizations.

The social scientists were academics, whose starting point was research into human behaviour in workplace. Most of their studies were initially linked to concerns about efficiency including the effects of physical working conditions on employees. Subsequently there was a paradigm shift to human factor at work especially employee motivation, interpersonal communication and leadership style.

Modern exponents of contingency theory - embraces such factors as organization mission, vision, culture and values, organizational structure, leadership, external environment, and customer satisfaction. The belief here is to predict which conditions are more likely to produce an organization more capable of meeting competing demands of various stakeholders in our educational system.

The worth of any educational system as an investment lies in its capability to continuously serve its customers (students, parents, employers or labour, the society) better and remain relevant. 
It is on the strength of the foregoing that the this paper is structured to prepare managers of today by introducing them to issues in contemporary management focusing mainly on strengthening their horizon on the applied management styles in the work environment, motivational variables in contemporary management, and team building in enhancing productivity and efficiency in our educational system.

\section{THE DIFFERENT TYPES OF MANAGEMENT STYLES}

There are several types of management styles when it comes to managing in the workplace, and the traits of the staff that you are managing will help to define the management styles you will use. However, for this study, we examined a few of the management styles adopted in recent times arising from issues of contemporary management in our present society.

\section{Autocratic Management Style}

An autocratic manager makes decisions without the consultation of others, instead serving as a dictator type in communicating orders because they like to be in control of situations. This style of management leads to work getting done on time because there are less people involved in the decision making process.

Most schools in the Benue state show a common denomination of this style of management as most decisions are taken by the principal without due consultation to all other parties involved as most schools are privately owned by individuals with the aim of making profit. In one of the interviews we had with a principal in one of the schools, he emphasized that, an opinion formed about a school is basically the quality of teaching offered, and collecting, gathering and measuring that opinion on a regular basis provides the crucial information that is needed to run a school. In a similar vein, some proprietors of some schools argued that inasmuch as the students are the final judge of quality offered, the obvious thing to do is to ask them what specific aspect of service is most important to them.

In a related research conducted at Texas A\&M University, by Parasuraman, Zeithaml and Berry (1988) to determine the perception of service quality, it was discovered that, management only needs to be reliable, credible, attractive, responsive and empathic to keep customers satisfied. Once these ingredients are incorporated in the management style of an organization, end- users of such decisions will keep patronizing the value proposition offered. This style of management seems to be the best option to make a positive and lasting impression for shareholder's wealth. An organization that tries to be all things and listen to everything runs the high risk of becoming nothing to everyone hence the need to adopt this approach.

The problem with this type of management style is that the staff are going to eventually lost motivation working in an environment where they have no say and employee turnover is likely to run high as they move on to other opportunities where they can have an impact.

For situations or events where an on the spot decision needs to be made, this type of leadership can serve a purpose, but trying to have an autocratic style of management in place for long periods of time is just going to lead to headaches for all involved. This style of leadership is more suited for a prison setting or in the military as opposed to academic environment.

\section{Democratic Management Style}

A democratic manager is willing to share work with his staff by delegating it to get the job done. You are banking on the competency of your team to get the job done on time and to have it done correctly. The price of anything is the amount of life you exchange for it, for anyone who does what he must only when he is in the mood or when it is convenient is not going to be successful. Resources have little value unless you can pull from them the essentials that you need. In other words, good ideas are everywhere, but it is hard to see them when you won't look outside yourself. Maxwell (2012) emphasized this when he observed that, one of the keys to abundance is having a solutionoriented mind-set. A solution-oriented mind-set looks uninformed, and creates avenues of depending and earning from others. Peter F. Drucker was driven not by the desire to say something but the desire to learn something from every student he met-and that is why he became one of the most influential teachers most of us have ever known (Collins, 2005). The people you work with, and who know you in a way favorable way, will do more to determine your success, happiness, and level of achievement in life than any other single factor. It also a known fact that no one achieves everything positively by himself alone, but by involving others too. Every given job opportunity is meant to solve a problem and satisfy the needs of other people, and when others are giving similar opportunities it 
expands the level and quantum of work and problems to be solved, thereby reducing the stress that would have been placed on an individual coordinating the entire process.

Employees love this type of management style because they feel involved and are part of the process.

In delegating, management should ensure a good control system is put in place to see that that which is delegated is complied to. Maxwell (2012) asserts that, measurement is the first step that leads to control and eventually to improvement. If you cannot measure something, you can't understand it. If you can't understand it, you can't control it. If you can't control it, you can't improve it. The Hawthorne Effect study of the 1930s laid credence to this assertion. Researchers who conducted experiments in productivity at the Hawthorne works plant in Chicago in the 1930s discovered that when people knew their work was being measured, their productivity increased. The researchers therefore called that the Hawthorne Effect (Cole, 1996).

Delegation as a management principle makes a difference in workplace. It enables you set goals, evaluate progress, judge results, and diagnose problems. If management of schools could adopt this style of leadership, it will stimulate growth, and efficiency that help them follow through on everything they do.

In spite of the inter-dependability of ideas and initiatives in a democratic management set-up, the job performance of employees is likely to be better than in an autocratic setting, though giving them the authority to do the work may lead some to rely on others to bear the brunt of the work on the project.

Getting too many people involved in the project or process could slow the work down. It could also mean less time for you to concentrate on your work as your team asks questions and waits on your answers before proceeding to the next steps.

\section{Participative Management Style}

Also sometime known as consultative management style, this decision making style in management revolves around getting lot of feedback from your staff before coming to a conclusion and making a decision. When a system calls for personal initiatives from employees, they take it as a habit to be sowing thoughts that would elevate them amongst themselves. As rightly observed by Tracy (2003), from the time you get up in the morning to the time you go to sleep at night, your thoughts largely control the words you say, the things you do, and the ways you react and respond. In a similar vein, Drucker (2001) observed that, if you go to work on the goals you set, your goals will go to work on you. If you go to work on your plan, your plan will go to work on you. Whatever good you build will end up building you. We should also realize that everything is changing including customer's perception of services, and it will be only those schools that are smart enough to keep asking, adapting, and improving in accordance with what the parents/pupils think have the inside track to long-term prosperity.

It is worthy of note that, people who deal directly with customers of an organization can make or break the business, so involving employees in decision making helps solves important problems as they arise. Establishing a good communication rapport with employees brings in plenty of good ideas. Being a good listener means much more than simply hearing what people are saying, it means blocking out all distractions, giving the other person your undivided attention, and listening with your whole self.

LeBoeuf (1987) however remarked that, we should listen with three ears- listen to what they are saying, listen for what they are not saying and listen for what they would like to say but cannot put into words. Furthermore, as employees are involved in decision making, they are more educated being on top of situation as it arises. This means that the process can take a bit longer as there are more voices to be heard, but getting a consensus on major decisions can lead to buy in from those who might otherwise have been opposed to the implementation of such changes. Example, as most public schools in the state are trying to recover from the falling enrollment occasioned by the lukewarm attitude of the government that resulted to incessant strikes, management of such schools are using this approach to regain the lost glory as well as endear other employees put in their best to attract more patronage.

The downside to this style of management and leadership is that employees may feel that you don't value their opinion or are too stubborn if after all of the feedback is received, you go off and make the decision in your own without incorporating any of their feedback. 
If you are going to make institutional or departmental policy changes, this type of style can make the team feel involved and more apt to go with the flow of whatever changes are coming down. This style also works well for brainstorming sessions.

\section{Laissez Faire Management Style}

In this management style, the team is given the freedom to complete the job or tasks in any way they deem it should be done. It is a hand off approach at the management level in terms of direction, but the manager is there to answer questions and provide guidance as needed. This is a good way to help develop individual contributors into leaders which is only going to serve to make your team stronger in the long run.

It is very important in management never to ask people to try to accomplish goals they cannot achieve. When people are given the free will to work, it gives a strong satisfaction, and in turn goes a long way in building confidence and character. As rightly observed by Tracy (2003), every time you take action that builds your character, you become stronger as a person- the harder the task, the greater the character builder. For every positive action you take helps you to believe in yourself, which in turn helps you to take more positive action. As individual worker achieve a positive result, management should be encouraged celebrating such employee, as it helps to inspire him keep going. Claude (1994) sees wealth and opportunities are contained more in the person they are and the way they think than the assets acquired over time in life. What this implies is that, the future lies more in your ability to apply your mind and intelligence to your work and life than it does in current job or situation. Invariably, when individual employees are given the freedom to use their collective intelligence for the good of the organization, it will change the prospects of the business. The more different things an individual does, the more likely it is for you to do the right thing at the right time. Therefore, allowing employees try a lot of options create an atmosphere of hard work for success and more remuneration. That is why in 2003, the United States of America was rated as the most entrepreneurial country in the world because people were allowed to start and build successful businesses provided you have the needed resources (Tracy, 2003).

However, Thomas (2000) argued that employees under this style of leadership should know that success comes from good habits. For successful people form good habits and ensure that those habits govern their behaviors. While unsuccessful people allow bad habits to form, and these bad habits then lead to frustration and failure.

On the flip side, it can lead to conflict on the team if some employees try to assume the role as a leader in the interim or to dictate to others how work should be done.

\section{Total Quality Management (TQM)}

Total Quality Management (TQM) is management thinking brought about in the 1980s by an American statistician known as Edwards Deming (Stoner, Freeman and Gilbert, 2000:211). He looks at TQM as consisting of organization-wide efforts to install and make permanent a climate in which an organization continuously improves it ability to deliver high quality products and services to customers. Deming placed great importance and responsibility on management at both the individual and company level, believing management to be responsible for $94 \%$ of quality problems. He therefore advanced fourteen point philosophy of management that can apply to small or large organizations in public, private or service sectors:

i. $\quad$ Create constancy of purpose and continual improvement - long term planning must replace short term reaction.

ii. $\quad$ Adopt the new (Japanese) philosophy - by management and workers alike.

iii. $\quad$ Do not depend on (quality) inspection - build quality into the product and process.

iv. Choose quality suppliers over low cost suppliers - to minimize variation in raw materials and supply.

v. Improve constantly - to reduce variation in all aspects e.g. planning, production, and service.

vi. Training on the job - for workers and management, to reduce variation in how job is done.

vii. Leadership not supervision - to get people to do a better job, not just meets targets.

viii. Eliminate fear - encourage two-way communication, encourage employees to work in the organization's interest.

ix. Break down internal barriers - departments in an organization are "internal customers" to each other and must work together.

x. Eliminate slogans (exhortations) - processes make mistakes not people. Management harassment of workers will create bad relations if no effort is made to improve processes. 
xi. Eliminate numerical targets - management by objectives (targets) encourages low quality.

xii. Remove barriers to worker satisfaction - including annual appraisals.

xiii. Encourage self improvement and education for all.

xiv. Everyone is responsible for continual improvement in quality and productivity - particular top management.

The philosophy behind TQM is however to develop the culture of continuous improvement through employees; collaborative efforts for the satisfaction of customers (students, parents, teachers and community) needs. Most private schools have already started some form of TQM. In fact the good ones among them have demonstrated sensitivity for quality assurance through their teaching, extra lessons, parental involvement etc.

If some of these management philosophies are effectively applied in our schools, we will achieve increasingly better products and services.

\section{McGREGOR THEORY X and THEORY Y}

McGregor - Theory X and theory $\mathrm{Y}$ - Theory $\mathrm{X}$ and Theory $\mathrm{Y}$ are essentially sets of assumptions that underlie human behavior in workplace. The first set of assumptions regards employees as being inherently lazy, requiring coercion and control, avoiding responsibility and only seeking security. This attitude is what McGregor termed Theory X.

The second set of assumptions sees people in a more favourable light. In this case, employees are seen as liking work, which is natural as rest or play; they don't have to be controlled and coerced, so long as they are committed to the organization's objectives. In ideal situation, they will not only accept but also seek responsibility; more rather than less people are able to exercise imagination and ingenuity at work. These are the assumption of theory Y.

The work of McGregor has made tremendous impact in the managerial world and if properly applied in our educational system comprising of different types of human beings with their attendant traits and behaviour will yield positive results in enhancing productivity.

\section{TYPES OF MOTIVATIONAL PROGRAMMES FOR EMPLOYEES IN WORKPLACE}

There are many different ways a manager can go about motivating employees in the workplace, and there are several different reasons why coming up with an employee motivation is very important. Some few of such models are highlighted as:

\section{Maslow's Hierarchy of Needs}

Maslow's studies into human motivation led him to propose a theory of needs based on a hierarchical model with basic needs at the bottom and higher needs at the top (Maslow, 1987).

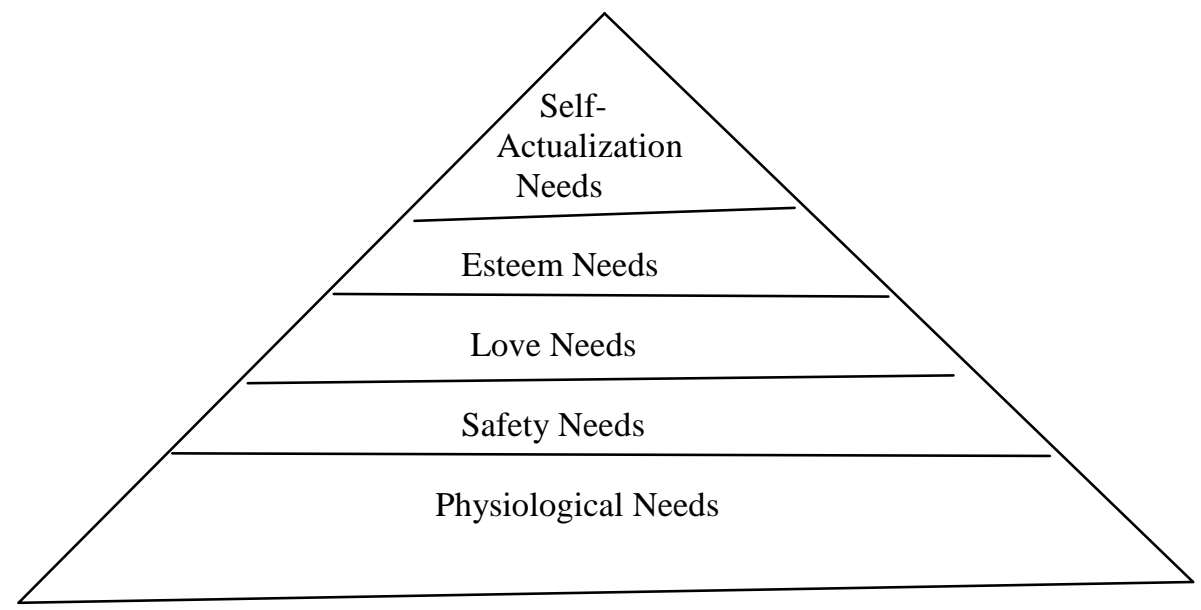


The starting point is that most people we motivated by the desire to satisfy specific groups of needs. These are:

i. Physiological Needs - needs for food, sleep, sex, shelter etc.

ii. Safety Needs - needs for a stable environment, force of threat.

iii. Love Needs - needs related affectionate relations with others and status within a group.

iv. Esteem Needs - needs for self respect, and the esteem of others.

v. Self-actualization Needs - the need for self fulfillment.

This theory when fully applied even in our educational system will have considerable influence on the quality of products produced, as well as building harmonious relationships between workers and management.

But where management fails to address these needs in a work environment may create a mis-match in achieving organizational goals and aspirations.

But caution should be taken as the theory has provided only a useful framework for the discussion of the variety of needs that people may experience in workplaces, and the ways in which their motivation can be met by managers.

Herzberg's Motivation - Hygiene Theory - the Theory is concentrated basically on satisfaction at work. The work led credence on one hand to factors that creates job satisfaction, while on the other hand, other factors that frequently lead to dissatisfaction. He then classified those factors that give rise to satisfaction as motivators, and those giving rise to dissatisfaction as hygiene factors (Herzberg, 1968).

The work of Herzberg is diagrammatically represented in the table below.

\begin{tabular}{|l|l|}
\hline $\begin{array}{l}\text { Factors leading to Extreme Dissatisfaction (HYGIENE } \\
\text { FACTORS) }\end{array}$ & Factors leading to Extreme Satisfaction (MOTIVATORS) \\
\hline Company policy and administration & Challenging work \\
\hline Quality of supervision & Achievement \\
\hline Working conditions & Recognition \\
\hline Salary & Responsibility \\
\hline Job security & Advancement \\
\hline Interpersonal relations & Growth \\
\hline
\end{tabular}

The hygiene factors (dissatisfier) will not motivate people in an organization: yet they must be present, or dissatisfaction will arise. The motivators have the potential of yielding a sense of satisfaction. Hygiene in a pure sense of it does not positively promote good health, but only acts to prevent ill health.

A good manager should be able to give considerable attention for job enrichment, i.e. the design of jobs so that they contain a greater number of motivators.

However, in our work environment as good as the motivators are simple and most implementable; most Chief Executives find it difficult to key into it. Example, most teachers at the secondary school level are hardly given challenging work and their level of growth and advancement on the job is absolutely slow. In order to achieve an effective management that will ensure quality, managers should imbibe these virtues as they greatly enhance productivity in the workplace.

\section{Equity Theory}

The basis of equity theory is that people make comparison between themselves and others in terms of what they invest in their work (inputs) and what outcomes they receive from it (output). In other words, an individual perceive the reward structure as being fair. The theory states that when people perceive an unequal situation, they experience "equity tension", which they attempt to reduce by appropriate behaviour. It may be a positive behaviour to improve performance and/or to seek improved rewards or even act negatively on grounds of being under-rated or underpaid. Example, the Nigerian educational system has been in a war with past administrations for not living up to expected standards as stipulated by regulating bodies.

But it should be realized that when people perceive an inequitable situation for themselves they can be predicated to make one of six choices.

i. $\quad$ Change their inputs

ii. Change their outcomes (increase their pay by producing higher quality. 


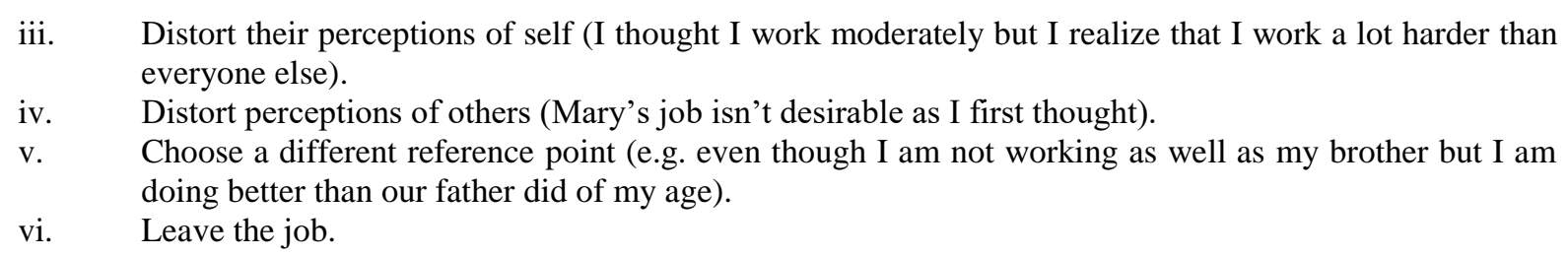

Managers should understand that people are interested in the comparative nature of rewards given.

\section{Team Building}

A team, according to Adair (1986), is more than just a group with a common aim. It is a group in which the contributions of individuals are seen as complementary. Collaboration, working together, is the keynote of a team activity. He suggests that the test of a good team is:

'whether... its members can work as a team while they are apart, contributing to a sequence of activities rather than to a common task, which requires their presence in one place and at one time'.

The school as an intellectual citadel requires teams in ensuring that decisions taken are geared towards uplifting the academic value of the society. From our personal experiences, team work has been an important option in our educational system that calls for critical brainstorming, which in most instances yields positive results. However for the team to be effective, the following variables have to be addressed.

- Clear objective and agreed goals

- Openness and confrontation

- Support and trust

- Cooperation and conflict

- Sound procedures

- Appropriate leadership

- Regular review

- Individuals development

- Sound intergroup relations

Adir further emphasized the importance of careful selection of team members. The key factors here for individuals are not only technical or professional competence, but also the ability to work as a team member, and the possession of 'desirable personal attributes' such as willingness to listen, flexibility of outlook, and the capacity to give and accept trust.

\section{Reasons why Teams or Groups are used}

1. Group deliberation and judgment - The advantage of gaining group deliberation and judgment - a variation of the adage that "two heads are better than one".

2. Representation of interested groups - members of a team are fairly selected in order have a representation of interested parties in an operation.

3. Coordination of departments, plans and policies - There is a general belief that groups are very useful for coordinating plans and policies as well as their implementation.

4. Motivation through participation - teamwork permit wide participation in decision making thereby making them feel more enthusiastic about accepting and executing it.

\section{Tips for Team Building}

According to Heathfield (2017) (http//www.thebalance.com/tips-for-team-building 1918512), there are tips for team building in the workplace that enhance productivity and efficiency. These include:

Clear Expectations: Has executive leadership clearly communicated its expectations for the team's performance and expected outcomes? Do team members understand why the team is created? Is the organization demonstrating constancy of purpose in supporting the team with resources of people, time and money? Does the work of the team receive sufficient emphasis as a priority in terms of the time, discussion, attention and interest directed its way by executive leaders? 
Context: Do team members understand why they are participating on the team? Do they understand how the strategy of using teams will help the organization attain its communicated business goals?

Commitment: Do team members want to participate on the team? Do team member feel the team mission is important? Are members committed to accomplishing the team mission and expected outcomes? Do team members perceive their service as valuable to the organization and to their own careers? Do team members anticipate recognition for their contributions? Do team members expect their skills to grow and develop on the team? Are team members excited and challenged by the team opportunity?

Competence: Does the team feel that it has the appropriate people participating? Does the team feel that its members have the knowledge, skill and capability to address the issues for which the team was formed? If not, does the team have access to the help it needs? Does the team feel it has the resources, strategies and support needed to accomplish its mission?

Charter: Has the team taken its assigned area of responsibility and designed its own mission, vision and strategies to accomplish the mission. Has the team defined and communicated its goals; its anticipated outcomes and contributions; its timelines; and how it will measure both the outcomes of its work and the process the team followed to accomplish their task? Does the leadership team or other coordinating group support what the team has designed?

Control: Does the team have enough freedom and empowerment to feel the ownership necessary to accomplish its charter? At the same time, do team members clearly understand their boundaries? How far may members go in pursuit of solutions? Are limitations (i.e. monetary and time resources) defined at the beginning of the project before the team experiences barriers and rework?

Collaboration: Does the team understand team and group process? Do members understand the stages of group development? Are team members working together effectively interpersonally? Do all team members understand the roles and responsibilities of team members?

Communication: Are team members clear about the priority of their tasks? Is there an established method for the team to give feedback and receive honest performance feedback? Does the organization provide important business information regularly?

Creative innovation: Is the organization really interested in change? Does it value creative thinking, unique solutions, and new ideas? Does it reward people who take reasonable risks to make improvements? Or does it reward the people who fit in and maintain the status quo? Does it provide the training, education, access to books and films, and field grips necessary to stimulate new thinking?

Consequences: Do team members feel responsible and accountable for team achievements? Are rewards and recognition supplied when teams are successful? Is reasonable risk respected and encouraged in the organization? Do team members fear reprisal? Do team members spend their time pointing rather than resolving problems? Is the organization designing reward systems that recognize both team and individual performance? Is the organization planning to share gains and increased profitability with team and individual contributors? Can contributors see their impact on increased organization success?

Coordination: Are teams coordinated by a central leadership team that assists the groups to obtain what they need for success?

\section{Successful Guidelines for Team Building}

The following factors are also very useful in team building:

Authority - A team's authority should be spelled out so that the members know whether their responsibility is to make decisions, make recommendations, or merely deliberate and give the person concerned some insights into the issue under discussion. 
Size -If the team is too large, there may not be enough opportunities for adequate communication among its members. On the other hand, if the team consists of only three persons, there is the possibility that two may form a coalition against the third member.

Membership -The members of a team must be selected carefully. If a group is to be successful, the members must be representative of the interests they are expected to serve.

Subject Matter -The subject must be carefully selected. Team work should be limited to subject matter that can be handled in group discussion.

Cost Effectiveness -A team must be worth its cost.

\section{The Challenges of Team Work}

The challenges of team work may include amongst others the following:

Tendency of be Self-Destructive

Indecisiveness may give the chairperson or a strong member an opportunity to force the team into a decision the way he or she wants it to go. Almost invariably, one person in a group emerges as the leader.

\section{Splitting of Responsibility}

When authority to study a problem, make recommendations, or arrive at a decision is delegated to a group, the fact is that the authority is dispersed throughout the group. Thus, individual members hardly feel the same degree of responsibility that they would if they personally were charged with the same task.

Tyranny by a Few Persons

As has been pointed out, teams tend to seek unanimous or nearly unanimous conclusions or decisions. A few members who may represent a minority view are thus in a strong position to impose their will on the majority of members.

\section{CONCLUSION}

The desire for quality education in Benue state is a general shared feeling of the people. But the ability to achieve success against all odds is key to an effective leadership. Though, quality leadership is more of an internal instinct that becomes effective in our leadership activities on the outside. As enunciated by Deming, to ensure quality and efficiency in an organization, the style of management is responsible for only $35 \%$, while the internal composition comprise of almost $65 \%$. But it should be realized that as there are many different management styles, each of them can serve a purpose depending on the type of organization and environment you are in, as well as the situation at hand. The most effective management styles are those which you can take bits and pieces from to combine with your own natural management thinking to create a stress-free and productive work environment.

\section{References}

[1]. Adair, J. (1986). Effective Team-building. Gower.

[2]. Claude, B. (1994). The Magic of Believing. New York: Pocket Books.

[3]. Cole, G.A. (1996). Management Theory and Practice, $5^{\text {th }}$ ed. U.K. Ashford Color Press.

[4]. Collins, J. (2005, September $\left.28^{\text {th }}\right)$. Lessons from a Student Life. Businessweek.

[5]. Drucker, P.F. (2001). Management Challenges for the $21^{\text {st }}$ Century. New York: Harper Business.

[6]. Heathfield, S.M. (2017 Updated March $10^{\text {th }}$ ). http//www.thebalance.com/tips-for-team-building 1918512. Downloaded on the $2^{\text {nd }}$ March, 2018.

[7]. Herzberg, F. (1968). Work and the Nature of Man. Staples Press (GB).

[8]. LeBoeuf, M. (1987). How to Win Customers and Keep Them for Life. Lagos- Nigeria: Pastoral Care Publishing.

[9]. Maslow,A. (1987). Motivation and Personality, $3^{\text {rd }}$ ed., Harper \& Row.

[10]. Parasuraman, A., Zeithaml, V. \& Berry, L. (1988). SERQUAL: A multiple-item scale for measuring customers' perception of service quality. Journal of Retailing, 64 (1). 
[11]. Stoner, J.A.F., Freeman, R.E. and Gilbert, D.R. (2000). Management. $6^{\text {th }}$ ed., New Delhi: Prentice -Hall of India Private Ltd.

[12]. Thomas, S. (2000). The Millionaire Mind. Kansas City, MO: Andrews McMeel Publishing.

[13]. Tracy, B. (2003). Goals. San Francisco, CA: Berrett-Koehler Publishers.

[14]. Weihrich, H. and Koontz, H. (1993). Management: A Global Perspective. New York, U.S.A.: Mc-Graw Hill International. 